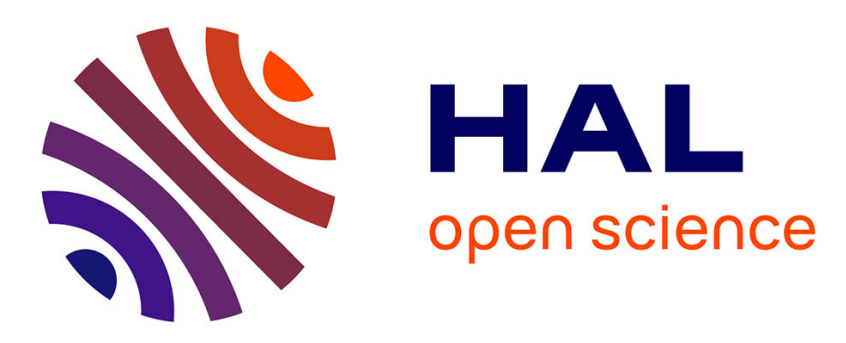

\title{
Application of a magnetic suspension balance to the oxidation study of the zirconium based alloys under high pressurewater vapour
}

Yacoub Dali, Marc Tupin, Philippe Bossis, Michèle Pijolat, Françoise

Valdivieso

\section{To cite this version:}

Yacoub Dali, Marc Tupin, Philippe Bossis, Michèle Pijolat, Françoise Valdivieso. Application of a magnetic suspension balance to the oxidation study of the zirconium based alloys under high pressurewater vapour. Journal of Thermal Analysis and Calorimetry, 2009, 96 (1), pp.155-160. 10.1007/s10973008-8901-x . hal-00408986

\section{HAL Id: hal-00408986 https://hal.science/hal-00408986}

Submitted on 4 Aug 2009

HAL is a multi-disciplinary open access archive for the deposit and dissemination of scientific research documents, whether they are published or not. The documents may come from teaching and research institutions in France or abroad, or from public or private research centers.
L'archive ouverte pluridisciplinaire HAL, est destinée au dépôt et à la diffusion de documents scientifiques de niveau recherche, publiés ou non, émanant des établissements d'enseignement et de recherche français ou étrangers, des laboratoires publics ou privés. 
Application of a magnetic suspension balance to the oxidation study of the zirconium based alloys under high pressurewater vapour

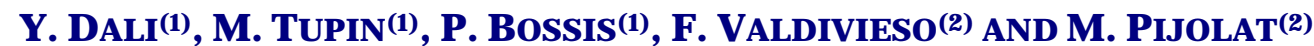

(1) CEA Saclay, DEN/DANS/DMN/SEMI/LM2E, 91191 Gif sur Yvette Cedex, France

(2) Ecole Nationale Supérieure des Mines, LPMG, URA CNRS 2021, Centre SPIN, 158 Cours Fauriel, 42023 SaintEtienne, Cedex 2, France

\section{Abstract}

The fuel claddings in the Pressurised Water Reactor are corroded in water at high temperature and high pressure. The technical device ableto follow continuously the corrosion rate in conditions close to this medium does not yet exist. That is the reason why a high pressure thermogravimetric installation based on magnetic suspension has been designed to study in situ the oxidation kinetics of the zirconium based alloys under water vapour until 50 bars of pressure at $415^{\circ} \mathrm{C}$. The accuracy of measurements is about $5 \cdot 10^{-5} \mathrm{~g}$ under 2 bars, and $10^{-4} \mathrm{~g}$ under 50 bars. The reproducibility of measurements was verified and the deviation regarding post test weighing at room temperature is around $5 \cdot 10^{-5} \mathrm{~g}$ what is clearly satisfying. Finally, the results presented in this work allow validating the high pressure thermogravimetric measurements obtained with this magnetic suspension device.

Keywords: high pressure ; kinetics ; magnetic suspension ; oxidation ; steam ; thermogravimetry ; Zircaloy-4

\section{Introduction}

Zirconium based alloys are widely used as cladding material for fuel rods of water-cooled nuclear reactors because of their low neutron capture cross-section, good corrosion resistance in operating conditions and satisfying mechanical properties. The first family of zirconium based alloys is the Zircaloys, starting with Zircaloy1, a sponge zirconium containing 1.5 mass\% Sn. Tin was added to eliminate the negative effect of nitrogen. This element increases the strength but reduces the corrosion resistance [1]. A hazardous pollution of a Zircaloy-1 with an austenitic stainless steel $(18 \% \mathrm{Cr}$ and $8 \% \mathrm{Ni}$ ) led to the alloy called Zircaloy-2 which contains $1.2-1.7 \mathrm{mass} \%$ of Sn, 0.07-0.2 mass\% Fe, 0.05-0.15 mass\% Cr, 0.09-0.16 mass\% O and 0.03-0.08 mass\% Ni. Chromium and iron improve the corrosion resistance in water and steam, and the nickel improves the corrosion resistance in steam [2]. The last alloy developed is the Zircaloy-4 which does not contain any nickel because of its detrimental role in the hydrogen absorption [3].

Numerous studies in the last decades were performed to develop these alloys and to elucidate their particular corrosion kinetic behaviours [4]. For the first kinetic regime called the pre-transition, it is generally assumed that the growth of the oxide during this stage is controlled by the diffusion of the oxygen through the oxide. The mass gain curve in this case corresponds to a sub-parabolic law [5]. After this period, an acceleration of the mass gain results in the change in the oxide morphology. This phenomenon is called kinetic transition. Finally the mass gain law tends to become linear.

The oxidation mechanism of Zircaloy-4 is not yet well understood. For a long time, studying the corrosion process of zirconium alloy in high temperature and high pressure conditions has been done by discontinuous measurements of the mass gain. To improve the understanding of this corrosion process it is of great interest to perform at high pressure steam in situ measurements. Recently, we designed and built a new experimental device, based on a Rubotherm magnetic suspension balance, that allows to access continuously to the mass gain during the oxidation of zirconium based alloys in pure water vapour under high pressure. In this paper, experimental installation will be presented in first place and its principle will be detailed. Secondly, the qualifications tests will be described and analyzed.

Previously, some classical thermogravimetric microbalance tests on zirconium alloys were carried out but only at low partial pressure [6,7]. For high pressure, the corrosion experiments performed in autoclaves consist of discontinuous mass gain measurements at different oxidation time. The only way to follow in situ the mass gain in these extreme conditions is to separate the balance and the measurement cell, from the corrosive medium and to couple magnetically the balance to the sample as proposed by Gast in 1959 [8, 9].

\section{Experimental}

As described in Figure 1 the high pressure water vapour device is made up of different parts:

\section{Steam generator}

The steam generator consists of a one-liter autoclave connected to different atmospheres, inert gas (helium or argon), mixed helium-oxygen at 20\% and diluted hydrogen at $3 \%$ in helium. The temperature, the hydrogen 
partial pressure and the whole pressure are controlled by thermocouples and pressure sensors. With this autoclave 150 bars of pure water vapour can be generated (maximal pressure of the Magnetic Suspension Balance (MSB)).

\section{Heating system}

The oxidation experiments are done around $400-450^{\circ} \mathrm{C}$ under high pressure steam. A three-zone furnace guarantees an isothermal zone of about $12 \mathrm{~cm}$, covering the entire surface of tested samples $(2 \cdot 10 \mathrm{~cm})$. Heating collars surrounding the different connecting tubes (reaching $400^{\circ} \mathrm{C}$ ) allow to avoid condensation. They are regulated to be always over the water liquid-vapour equilibrium temperature.

\section{Magnetic suspension balance}

Developed by RUBOTHERM and based on a magnetic coupling system, the magnetic suspension balance is composed of:

- the microbalance (accuracy of $10^{-5} \mathrm{~g}$ );

- the electromagnet;

- the magnetic suspension composed of a permanent magnet, a sensor core and a coupling cone;

- the coupling house at which the sample is hung via a platinum wire.

The electromagnet is suspended to the microbalance, and maintains in levitation the magnetic suspension.

As shown on Figure 2, three positions are used to perform the mass gain measurements:

- OFF position: the magnetic suspension is not attracted by the electromagnet and so lays down on the coupling house;

- Zero position (ZP): there is no coupling between the magnetic suspension and the sample, this position corresponds to the tare;

- Measure position (MP): the sample is coupled to the magnetic suspension; the mass of the sample is deduced from the current flowing in the electromagnet (and measured in this position by the microbalance).

The succession of the two positions (ZP-MP) leads to in situ acquirement of the mass gain.

\section{Thermostating circuit}

As described in the Figure 1, two thermostating circuits are used in this experiment. In the first one, a special high temperature oil flows inside the double wall chamber that allows to maintain the temperature up to $315^{\circ} \mathrm{C}$ in this part of the device and thus to avoid the water condensation. The second circuit is a cooling one; liquid water at $15^{\circ} \mathrm{C}$ flows inside a cooler diaphragm placed underneath the microbalance limiting the temperature in the microbalance. The circulation of the cold water is performed by a cryothermostat.

\section{Pressure and temperature sensors}

A two points temperature sensor is localised underneath the sample. These thermocouples allow the acquisition of two temperatures near the sample (the points are $5 \mathrm{~cm}$ apart). The temperature of the double wall chamber is controlled by an external thermocouple Two pressure sensors - connected to the autoclave cell - allow measuring the variation of the hydrogen pressure and of the total pressure (water vapour, inert gas and hydrogen).

\section{Connecting tubes and valves}

All the connections and valves are in a stainless steel tube adapted to high temperature and high pressure conditions, the introduction of gases in the tube-reactor is regulated by a high temperature and high pressure long valve (AT231).

\section{Data acquisition}

The Mess pro software allows to operate manually and also to perform measurement by programming different time segments (the maximum acquisition time is 2 months). All the electronic components are connected to the microbalance at ambient conditions.

\section{Qualification tests}

Specific tests have been performed to validate the experimental measurements, in particular signal accuracy, and to estimate the temperature stability, the buoyancy effect, the signal reproducibility and the effect of natural convection. The qualification tests were conducted on a Zircaloy-4 experimental alloy (sheet of $0.5 \mathrm{~mm}$ thickness) provided by AREVA NP CEZUS. Its composition is given in Table 1.

\section{Signal accuracy}

To validate the mass gain values measured by the thermobalance (magnetic suspension balance), three corrosion experiments at $415^{\circ} \mathrm{C}$ and different pressures have been performed on Zy4. These values of mass gains have been compared to mass variations of the samples measured after and before the corrosion with a classical balance (Sartorius) working at room temperature. The mass gain values obtained with the two techniques and their discrepancy are given in Table 2. 


\begin{tabular}{|c|c|c|c|c|c|}
\hline & $\mathrm{Sn} /$ & $\mathrm{Cr} /$ & $\mathrm{Fe} /$ & $\mathrm{O} /$ & $\mathrm{Zr} /$ \\
\hline Alloy & & & $\mathrm{Mass} \%$ & & \\
\hline Zircaloy-4 & 1.46 & 0.107 & 0.22 & 0.126 & $\mathrm{Bal}$ \\
\hline
\end{tabular}

Table 1: Chemical composition of the studied alloy

\begin{tabular}{|c|c|c|c|c|c|c|c|}
\hline \multicolumn{3}{|c|}{ 'Ordinary' balance } & \multicolumn{3}{c|}{ Thermobalance } & \multicolumn{2}{c|}{ Mass difference } \\
\hline $\mathrm{P} / \mathrm{bar}$ & initial mass/g & $\begin{array}{c}\text { final } \\
\mathrm{mass} / \mathrm{g}\end{array}$ & $\Delta \mathrm{m}_{1} / \mathrm{g}$ & $\begin{array}{c}\text { initial } \\
\text { mass } / \mathrm{g}\end{array}$ & $\begin{array}{c}\text { final } \\
\text { mass } / \mathrm{g}\end{array}$ & $\Delta \mathrm{m}_{2} / \mathrm{g}$ & $\Delta \mathrm{m}_{2}-\Delta \mathrm{m}_{1} / \mathrm{g}$ \\
\hline 2 & 8.10108 & 8.11145 & 0.01037 & 10.21394 & 10.22435 & 0.01041 & 0.00004 \\
\hline 10 & 8.13409 & 8.14889 & 0.0148 & 10.23718 & 10.25195 & 0.01477 & -0.00003 \\
\hline 50 & 7.87105 & 7.88219 & 0.0114 & 9.95504 & 9.96155 & 0.01115 & 0.00001 \\
\hline
\end{tabular}

Table 2: Mass gains obtained with balance at room temperature ('ordinary' balance) and with thermobalance for experiments at different pressures

It should be noticed that about $2 \mathrm{~g}$ difference in mass between the ordinary balance and the thermobalance comes from the fact that the mass measured by the microbalance takes into account the mass of the sample but in addition the mass of the hook and the coupling house. From Table 2, the mass gain determined by the ordinary balance is in good agreement with the mass variation measured with the thermobalance. In consequence, the signal accuracy of our experimental device is validated up to 50 bars.

\section{Stability of temperature}

Our experiments are generally done under isothermal conditions over a long time period. That is the reason why different tests were done to verify the thermal stability inside the tube-reactor with a thermocouple located $1 \mathrm{~cm}$ underneath the sample. The temperature variations during 10 days of experiment for different temperature plateaus are shown in Figure 3. The temperature fluctuations do not exceed $\pm 2{ }^{\circ} \mathrm{C}$ during the isothermal plateau, and temperature stability is consequently relatively satisfying.

Buoyancy effect

Doing experiments under high pressures needs a quantification of the buoyancy effect. Indeed, by increasing the pressure, the density of the reactive gas changes leading to an apparent decrease in the mass gain as observed in Figure 4 for five pressure plateaus at respectively $19,30,50,80$ and 100 bars, at $415^{\circ} \mathrm{C}$. The apparent mass loss resulting from the buoyancy effect can be theoretically calculated and then compared to the experimental results.

\begin{tabular}{|c|c|c|}
\hline Pressure increase/bar & $\begin{array}{c}\text { Cal. Mass loss due to the } \\
\text { buoyancy/g }\end{array}$ & $\begin{array}{c}\text { Mass loss given by the } \\
\text { experimental results/g }\end{array}$ \\
\hline $19-30$ & $4.210^{-3}$ & $5.510^{-3}$ \\
\hline $30-50$ & $8.910^{-3}$ & $9.010^{-3}$ \\
\hline $50-80$ & $14.810^{-3}$ & $2010^{-3}$ \\
\hline $80-100$ & $11.310^{-3}$ & $1110^{-3}$ \\
\hline
\end{tabular}

Table 3: Values of loss mass, theoretically calculated and experimentally measured

Table 3 and Figure 5 sum up the experimental mass loss and the calculated one considering the Archimedes' principle. The apparent mass change during a pressure change from P1 to P2 due to buoyancy was calculated by the following formula (1):

$$
|\Delta m|=V \times\left|\rho\left(P_{2}, T\right)-\rho\left(P_{1}, T\right)\right|
$$

where $\Delta \mathrm{m}$ is the mass variation during the pressure drop $(\mathrm{mg}), \mathrm{V}$ the volume of the object $\left(\mathrm{cm}^{3}\right)$, and $\rho\left(\mathrm{P}_{1}, \mathrm{~T}\right)$ and $\rho\left(\mathrm{P}_{2}, \mathrm{~T}\right)$, the densities of the steam, respectively at the pressures $\mathrm{P}_{1}$ and $\mathrm{P}_{2}$ and the temperature $\mathrm{T}\left(\mathrm{mg} \mathrm{cm}^{-3}\right)$. For instance, for the pressure change from 30 to 50 bars, we have to take into account the buoyancy effect on the masses of the sensor coil, the coupling house and the sample. But all these components are not submitted to the same temperature, the sensor coil and the coupling house are actually at $320^{\circ} \mathrm{C}$ while the sample is corroded at $415^{\circ} \mathrm{C}$. Consequently, the mass variations per volume unit are not the same because the steam densities are different at these temperatures. For this pressure drop, the mass loss can be detailed for each component:

- sensor coil:

$|\Delta \mathrm{m}|=\mathrm{V} \times \mid \rho\left(5 \mathrm{ob}, 320^{\circ} \mathrm{C}\right)-\rho\left(3 \mathrm{ob}, 320^{\circ} \mathrm{C}\right)=0.82 \times(20.8-10.8)=0.82 \mathrm{mg}$ with $\mathrm{V}=0.82 \mathrm{~cm}^{3}$

- coupling house:

$|\Delta \mathrm{m}|=\mathrm{V} \times \mid \rho\left(5 \mathrm{ob}, 32 \mathrm{O}^{\circ} \mathrm{C}\right)-\rho\left(3 \mathrm{Ob}, 32 \mathrm{O}^{\circ} \mathrm{C}\right)=0.23 \times(20.8-10.8)=2.3 \mathrm{mg}$ with $\mathrm{V}=0.23 \mathrm{~cm}^{3}$ 
- sample:

$|\Delta \mathrm{m}|=\mathrm{V} \times \mid \rho\left(5 \mathrm{ob}, 415^{\circ} \mathrm{C}\right)-\rho\left(3 \mathrm{ob}, 415^{\circ} \mathrm{C}\right)=0.85 \times(16.8-9)=6.6 \mathrm{mg}$ with $\mathrm{V}=0.85 \mathrm{~cm}^{3}$

The superheated water densities come from [10].

The masses measured during the ZP measurement step and the MP one describe respectively the mass loss of the sensor coil and those of the three preceding elements. The mass variations indicated on the Figure 5 correspond to the difference between the ZP measurement and the MP one. Thus the mass loss due to the buoyancy observed during the pressure drop results only from those calculated on the coupling house and the sample. It is equal to $8.9 \mathrm{mg}$ and is so very close to the experimental value (Table 5).

As shown on Figure 5, except for the surrounded point with approximately $20 \mathrm{mg}$, theoretical calculations are in relatively good agreement with the experimental results. It is so possible to correct the mass signal from the buoyancy effect during any experiment that includes temperature or pressure modification.

\begin{tabular}{|c|c|c|c|c|c|}
\hline \multicolumn{2}{|c|}{$\mathrm{T}=573^{\circ} \mathrm{C}$} & \multicolumn{2}{c|}{$\mathrm{T}-673^{\circ} \mathrm{C}$} & \multicolumn{2}{c|}{$\mathrm{T}=773^{\circ} \mathrm{C}$} \\
\hline $\mathrm{P} / \mathrm{bar}$ & $\mathrm{Ra}$ & $\mathrm{P} / \mathrm{bar}$ & $\mathrm{Ra}$ & $\mathrm{P} / \mathrm{bar}$ & 10 \\
\hline 10 & $610^{7}$ & 10 & $510^{7}$ & 10 & $310^{7}$ \\
\hline 50 & $310^{9}$ & 50 & $110^{9}$ & 50 & $810^{8}$ \\
\hline 100 & 11010 & 100 & $710^{9}$ & 100 & $410^{9}$ \\
\hline
\end{tabular}

Table 3: Calculated Rayleigh numbers under different conditions (with $\Delta T=100^{\circ} \mathrm{C}$ )

\section{Reproducibility test}

As illustrated in Figure 6, the measurements for two experiments performed in the same conditions $\left(415^{\circ} \mathrm{C}\right.$ and 2 bars) are clearly reproducible. The oxide thickness is deduced from the mass gain by the following formula (2):

$$
X=\frac{1}{S_{0}} \times \frac{M_{\mathrm{ZrO}_{2}} \Delta m}{P_{\mathrm{ZrO}_{2}} M_{\mathrm{O}_{2}}}
$$

where $\rho_{\mathrm{ZRO} 2}$ is the mass density of zirconia ( $5.6 \mathrm{~g} \mathrm{~cm}^{-3}$ for the monoclinic phase), $\mathrm{M}_{\mathrm{ZrO} 2}$ and $\mathrm{M}_{\mathrm{O} 2}$ are respectively the molar masses of zirconia and oxygen $\left(\mathrm{g} \mathrm{mol}^{-1}\right), \mathrm{S}_{\mathrm{o}}$ is the sample reacting surface $\left(\mathrm{cm}^{2}\right)$.

\section{Natural convection}

Natural convection phenomena are often frequent and observed during thermogravimetric measurements because of gas density variations inside the experimental system, related to cold points and more generally to temperature differences between two parts of the device. The Rayleigh adimensional number allows to estimate qualitatively the convection phenomena in a given experimental system. It is defined as follows:

$$
R_{a}=\frac{g \beta C_{p} \rho^{2} b^{3} \Delta T}{\eta K}
$$

with g: acceleration of gravity $\left(\mathrm{m} \mathrm{s}^{-2}\right), \beta$ : thermal expansion coefficient $\left(\mathrm{K}^{-1}\right), \mathrm{C}_{\mathrm{p}}$ : heat-storage capacity $\left(\mathrm{J} \mathrm{kg}^{-1} \mathrm{~K}^{-}\right.$ $\left.{ }^{1}\right), \rho$ : density $\left(\mathrm{kg} \mathrm{m}^{-3}\right)$, b: length of the nonisothermal zone $(\mathrm{m}), \Delta \mathrm{T}$ : temperature difference $(\mathrm{K}), \eta$ : dynamic viscosity of gas ( $\mathrm{Pa} \mathrm{s}), \mathrm{K}$ : thermal conductivity of gas $\left(\mathrm{W} \mathrm{m}^{-1} \mathrm{~K}^{-1}\right)$.

According to the literature [10], the threshold value of the Rayleigh number, beyond which the natural convection must be taken into account in this kind of reactors, is about 40000. Rayleigh number values were calculated for three different temperatures, 300, 400 and $500^{\circ} \mathrm{C}$, and three different pressures 10,50 and 100 bars applied to the sample, considering that the temperature difference (DT) between the magnetic suspension and the sample is in general around $100^{\circ} \mathrm{C}$. The results of these calculations are presented in Table 4.

The Rayleigh number increases with increasing pressure and the obtained values are always above the threshold which means theoretically that convection should take place in our tube-reactor. Whatever, when the pressure is above 30 bars, in practice, the convection currents disturb significantly the mass signal. For instance, as shown on Figure 7, the thickness variation vs. time for an isobaric experiment at 50 bars is relatively noisy compared to the one at 2 bars. For this pressure range, it is thus important to limit these convection currents as well as possible. In order to reduce the natural convection phenomena, the aim is to break the currents of convection flowing inside the reacting chamber, with a protection cage around the sample, by creating obstacles such as an alumina tube.

\section{Conclusions}

A high pressure thermogravimetric installation was developed allowing to study in situ the oxidation kinetics of the zirconium based alloys under pure water vapour until 50 bars of pressure at $415^{\circ} \mathrm{C}$. Accuracy of measurements 
is about $5 \cdot 10^{-5} \mathrm{~g}$ under 2 bars, and $10^{-4} \mathrm{~g}$ under 50 bars. The reproducibility of measurements was verified and the deviation regarding post test weighing measurements at room temperature is about $5 \cdot 10^{-5} \mathrm{~g}$.

\section{Acknowledgements}

The authors acknowledge the technical support from Paul Finet of SPECTRA SERIA and from Michael Holm of Rubotherm.

\section{References}

[1] B. G. Parfenov, V. V. Gerasimov and G. I. Venediktova, Corrosion of zirconium and zirconium alloys in Myers, New York 1967, p. 9.

[2] B. Cox, J. Nucl. Mater., 336 (2005) 331.

[3] E. Hillner, Hydrogen absorption in Zircaloy during aqueous corrosion, Effect of Environment, U.S. Rep.WAPD-TM-411, Bettis Atomic Power Lab, Pittsburgh 1964.

[4] International Atomic Energy Agency, Waterside Corrosion of Zirconium in Nuclear Power Plants,IAEATECDOC-996, IAEA, Vienna 1998, p. 37.

[5] P. Kofstad, High temperature corrosion in Elsevier Publishing, London-NewYork 1988, p. 299.

[6] M. Tupin, M. Pijolat, F. Valdivieso, M. Soustelle, A. Frichet and P. Barberis, J. Nucl. Mater., 317 (2003) 130.

[7] Pétigny-Putigny, Comparaison de l'oxydation de deux alliages à base de zirconium par diffraction des rayons $\mathrm{X}$ in-situ et ex-situ: texture, phase, contrainte, PhD thesis, Université de Bourgogne, Bourgogne 1998.

[8] Th. Gast and W. Pahlke, J. Thermal Anal., 37 (1991) 1933.

[9] Th. Gast and E. Robens, J. Thermal Anal., 47 (1996) 605.

[10] C. A. Meyer, ASME Steam Tables in American Society of Mechanical Engineers, New York, 1983.

[11] Sarrazin, A. Galerie and J. Foultier, Les mécanismes de corrosion sèche une approche cinétique in EDP Science, Paris, 2000, p. 44 


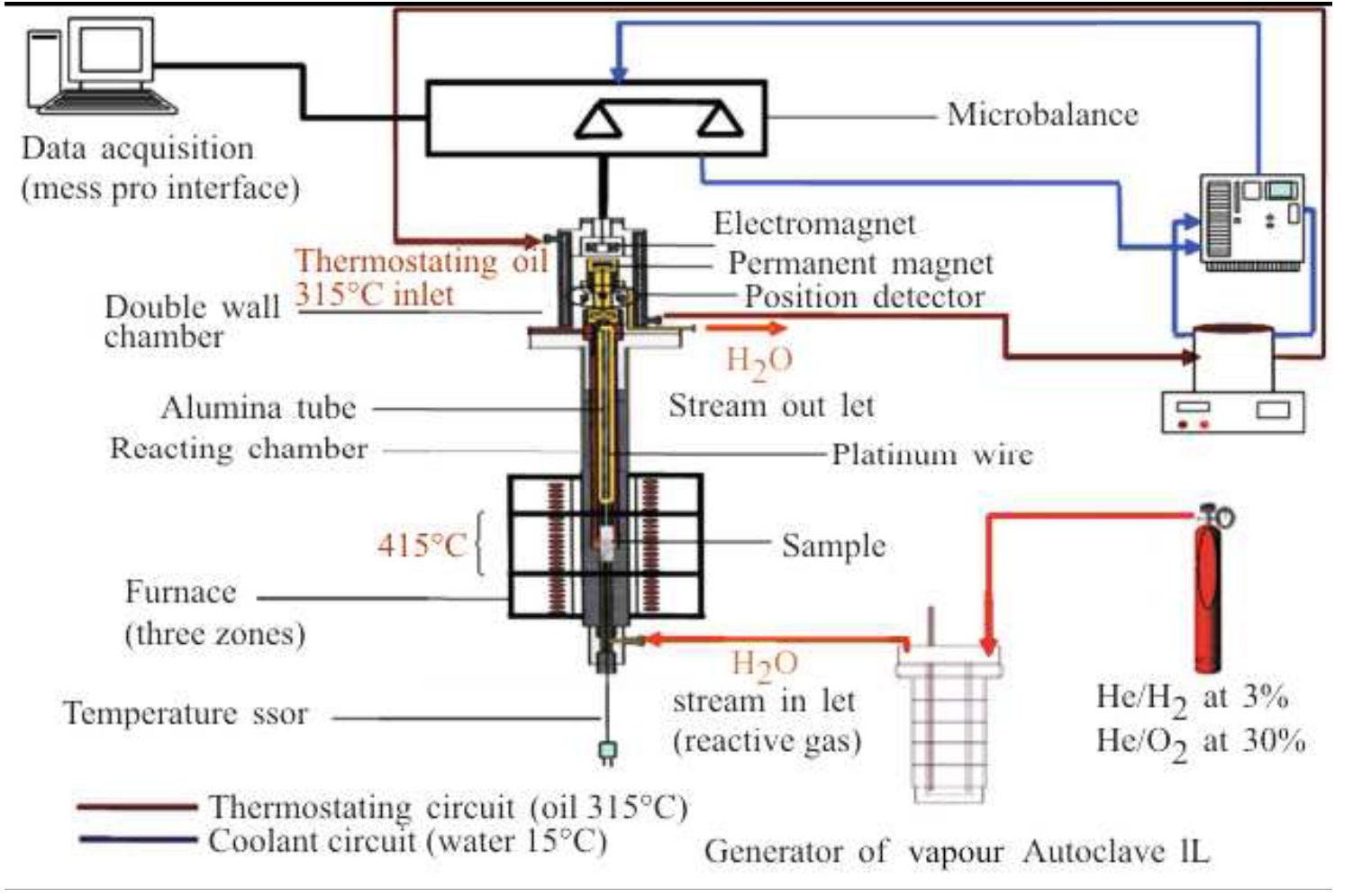

Figure 1: General scheme of the experimental device

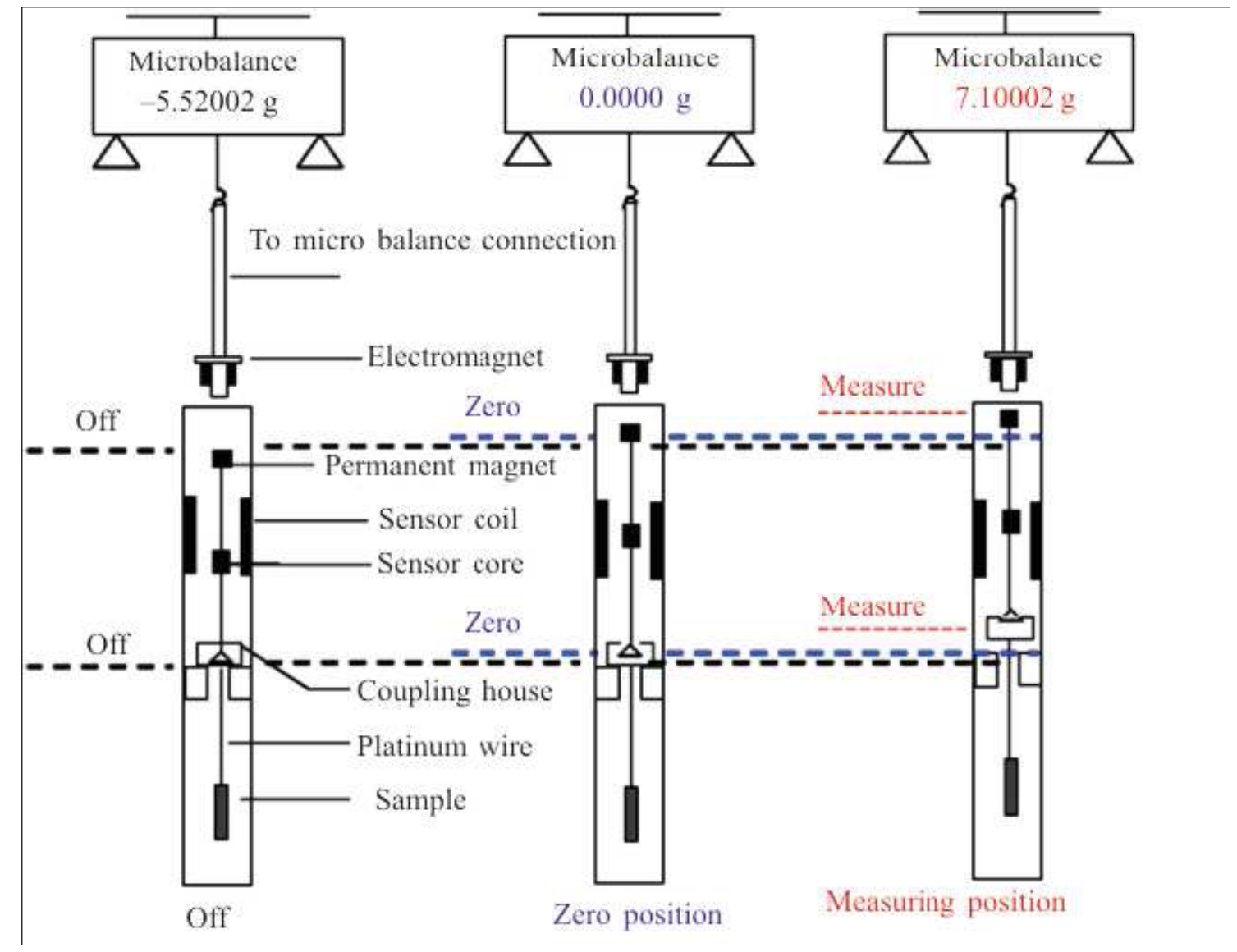

Figure 2 : Principle of the mass gain measurements by the magnetic suspension balance 


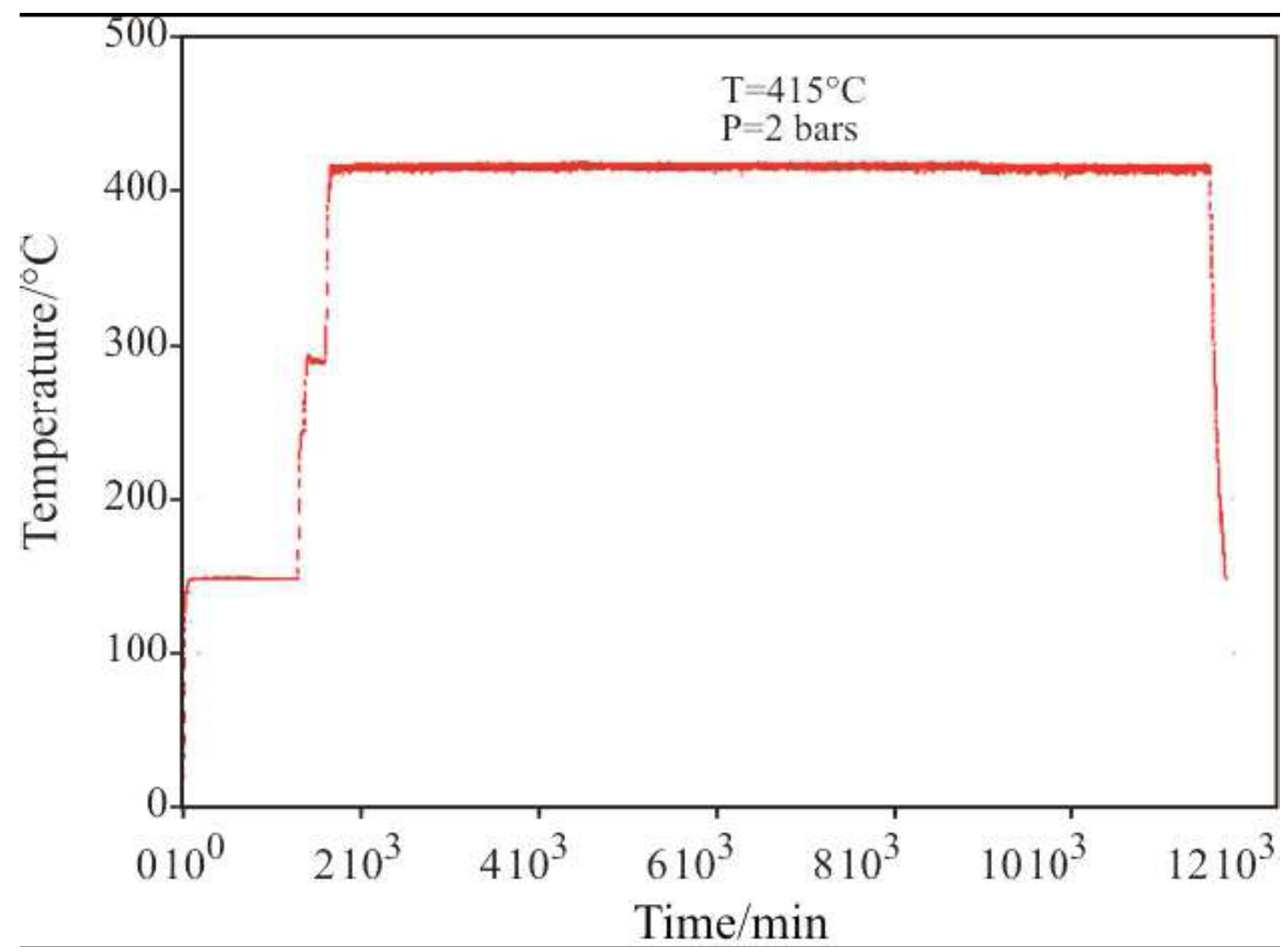

Figure 3: Temperature evolution for different isothermal plateaus ( $\mathrm{PH} 2 \mathrm{O}=2$ bar)

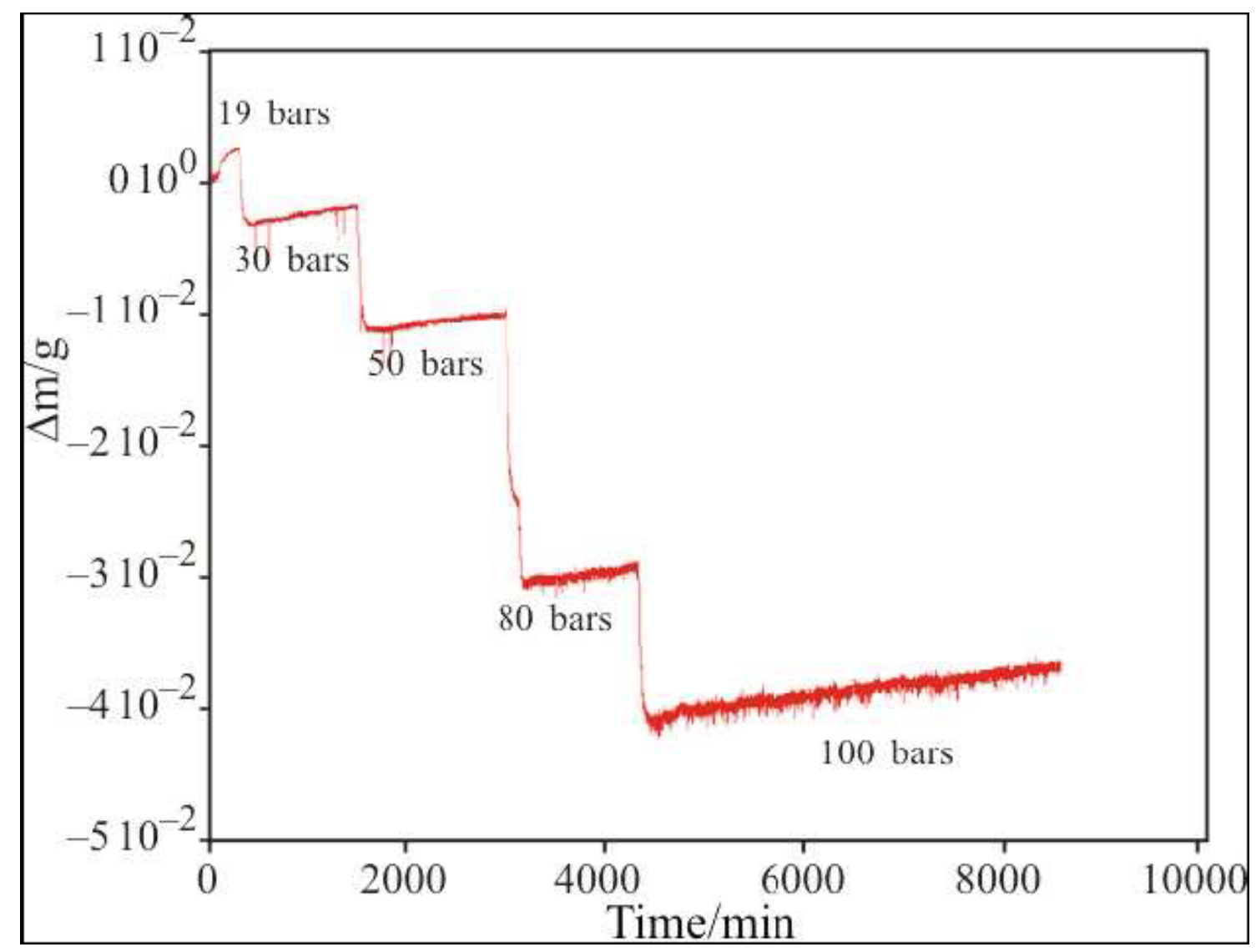

Figure 4 : Effect of pressure changes on the mass signal 


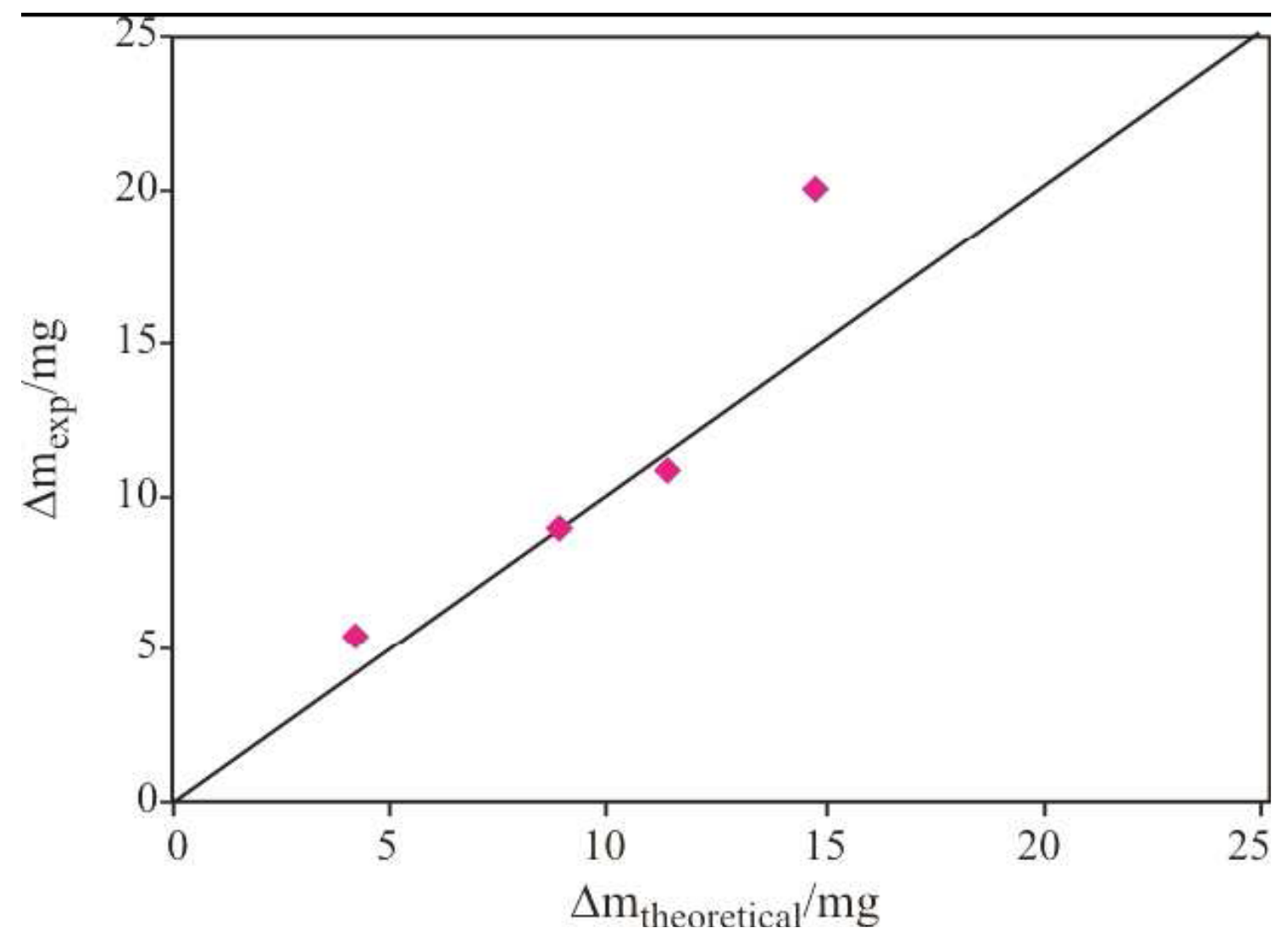

Figure 5: Comparison between the calculated and the experimental mass loss due to the pressure change

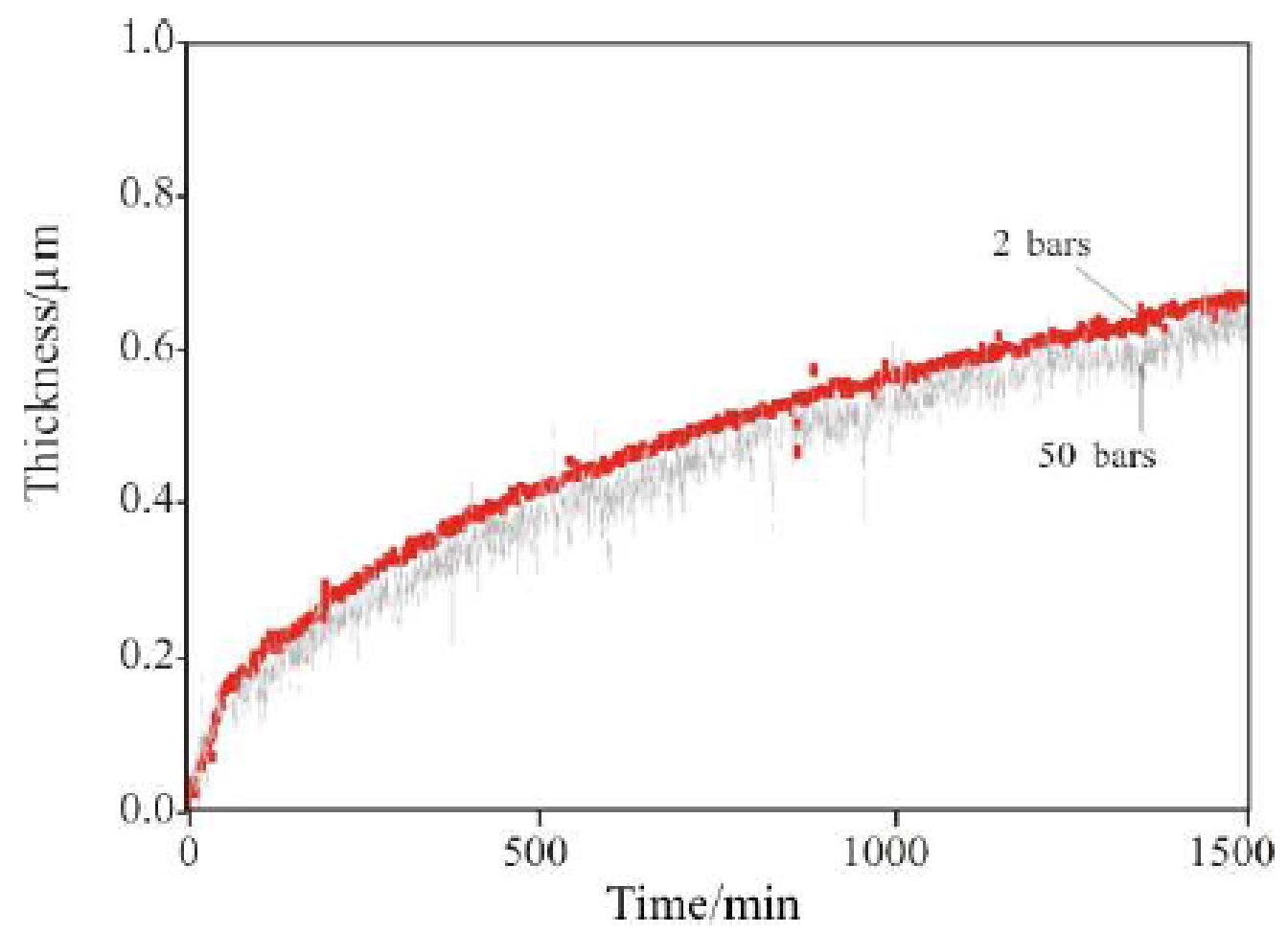

Figure 6 : Reproducibility of the thickness deduced from the mass signal obtained with the thermobalance during Zircaloy4 oxidation at $415^{\circ} \mathrm{C}$ and 2 bars 


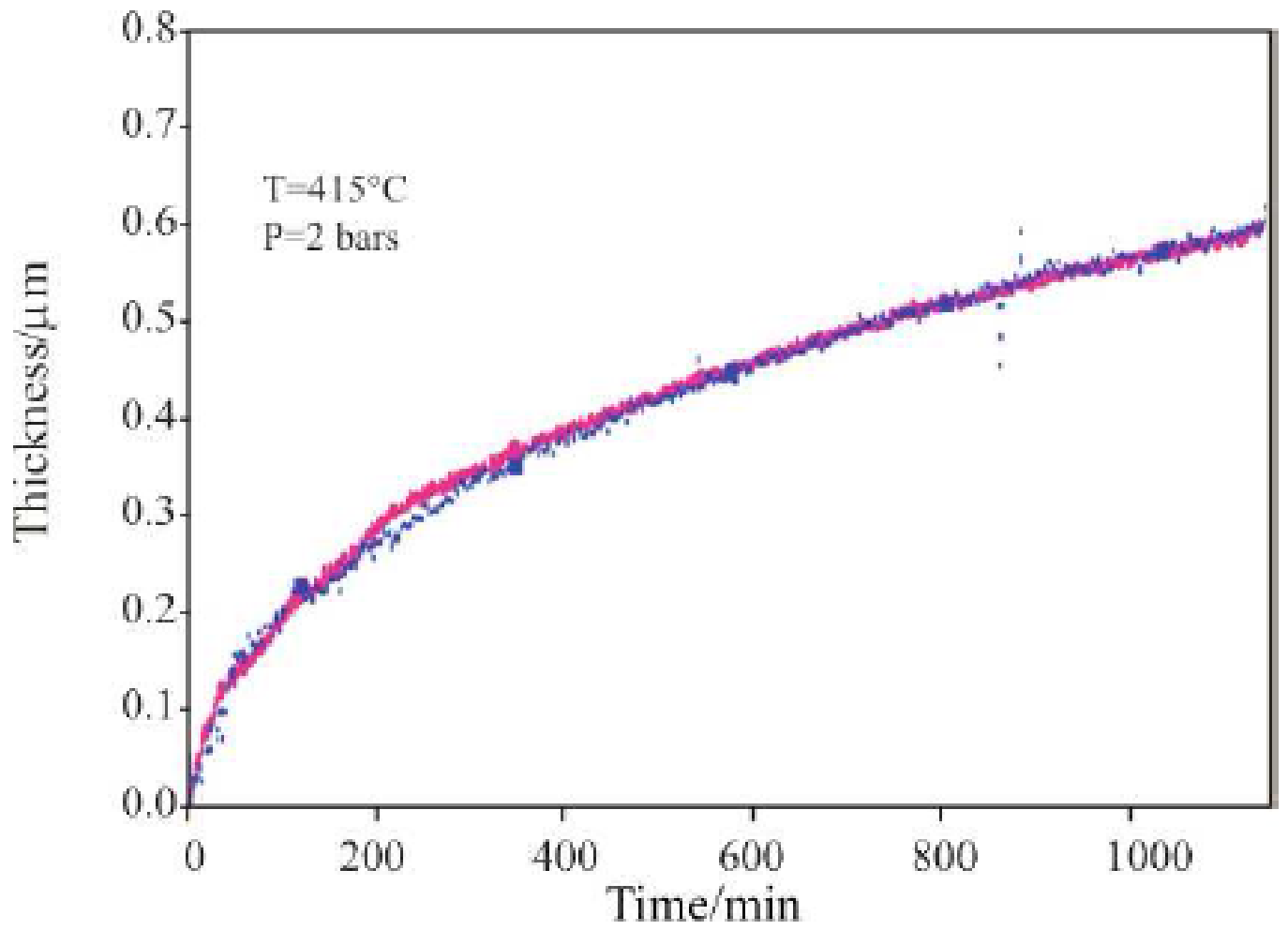

Figure 7: Oxide thickness variations of Zircaloy- 4 oxidized at $415^{\circ} \mathrm{C}$ under 2 bars and 50 bars of water vapour 